\title{
Application of near surface mounted (NSM) strengthening technique to traditional timber frame walls
}

Elisa Poletti ${ }^{1}$, Graça Vasconcelos, Marco Jorge

ISISE, Department of Civil Engineering, University of Minho, Campus de Azurém, Guimarães, Portugal

Corresponding author: Elisa Poletti

Email: elisapoletti@gmail.com

Phone: +351253510210

\begin{abstract}
Timber frame buildings are well known as an efficient seismic resistant structure popular all over the world not only due to their seismic performance, but also to their low cost and the strength they offer. These constructions still exist today and it is important to be able to preserve them, so a better knowledge on their behaviour is sought. Furthermore, historic technologies could be used even in modern constructions to build seismic resistant buildings using more natural materials with lesser costs.

A great rehabilitation effort is being carried out on this type of buildings, as their neglect has led to decay or their change in use and alterations to the structure has led to the need to retrofit such buildings; only recently studies on their behaviour have become available and only a few of them address the issue of possible strengthening techniques for this kind of walls.

In this scope, an innovative retrofitting technique (near surface mounted steel flat bars) is proposed and validated on traditional timber frame walls based on an extensive experimental program. The results of the static cyclic tests on distinct wall typologies retrofitted with the NSM technique are
\end{abstract}

\footnotetext{
${ }^{1}$ Current address: Nottingham Centre for Geomechanics, Faculty of Engineering, The University of Nottingham, University Park, Nottingham, NG7 2RD
} 
herein presented and discussed in detail. The main features on deformation, lateral stiffness, lateral resistance and seismic performance indexes are analysed.

Keywords: timber frame wall; cyclic test; NSM; stiffness; energy dissipation; damping

\section{Introduction}

In the past centuries, different sorts of natural materials have been used to build walls, such as mud, earth, straw, clay, cork and wood. Part of the constructive solutions is composed of masonry units produced with the above mentioned materials and various examples can be found through the centuries. Timber has often been associated to masonry as a complementary material to bind masonry. Timber frame walls combine these natural materials, creating a traditional structural element relatively cheap and which can be built with available materials: the infill can vary from regular masonry to mud and straw and various types of timber can be used, namely pine, chestnut or bamboo canes.

Timber frame walls are often adopted in seismic regions as shear walls, in order to resist to horizontal seismic actions. The particular geometry of the walls, with St. Andrew's crosses (concentric braced frame), is able to dissipate the energy generated by the earthquake motion and the timber structure that acts as a skeleton of the building should not suffer severe damages during the earthquakes [1] [2].

From several onsite investigations after the occurrence of recent earthquakes (Turkey 1999, Lefkas 2003, Kashmir 2005, Haiti 2010), it has been seen that timber frame buildings can be considered efficient seismic resistant structures adopted worldwide, often presenting less severe damages when compared to other types of structures [2] [3], including reinforced buildings (keeping in mind that construction quality influences these data). Nevertheless, their popularity is not only due to their seismic performance, but also to their low cost and the strength they offer, when compared to other traditional structures. In fact, this constructive system has been also used for centuries in regions of low seismicity. 
The origin of timber frame structures probably goes back to the Roman Empire, as in archaeological sites timber frame houses were found and were referred to as Opus Craticium by Vitruvius [4]. Timber frame constructions later spread not only throughout Europe, such as Portugal (edifícios pombalinos), Italy (casa baraccata), Germany (fachwerk), Greece, France (colombages or pan de bois), Scandinavia, United Kingdom (half-timber), Spain (entramados) etc., but also in India (dhaji-dewari), Turkey (himis and bagdadi), Peru (quincha), USA (balloon frame in Chicago), Haiti (Gingerbread houses) [4] [5]. A more extensive presentation of timber frame structures can be found in [6].

In Portugal, these structures were adopted after the devastating earthquake that hit Lisbon in 1755 for the construction of residential and commercial buildings, known as Pombalino Buildings, from the name of the prime minister of the time, the Marquis of Pombal, who encouraged the reconstruction of the city. A Pombalino building is characterized by external masonry walls and an internal timber structure, named gaiola (cage), which is a three-dimensional braced timber structure. The gaiola consists of horizontal and vertical elements and diagonal bracing members, forming the typical $\mathrm{X}$ of St. Andrew's crosses. Traditional connections used for the timber elements varied significantly in the buildings: the most common ones were mortise and tenon, half-lap and dovetail connections. Even though Pombalino buildings present a different structure that what encountered in other countries, e.g. Greece, Italy, Turkey, since they have external masonry walls, it is admitted a partial collapse of these while the building remains standing thanks to the timber cage.

Since timber frame structures constitute an important historical heritage in many city centres in the world, their conservation is of paramount importance. Many examples are available on restoration works done in traditional timber frame buildings, mainly concerning interventions due to decay of timber elements or change of use and alteration of the structure. Nevertheless, only few experimental studies have been performed in order to assess the efficiency of the strengthening techniques adopted. Numerous Pombalino buildings in Lisbon have been retrofitted using FRP sheets in the connections of the frontal walls, creating a star-shaped strengthening [5], or damping 
systems linked to frontal walls and to the outer masonry walls through injected anchors and providing additional bracing [5].

Cruz et al. [7] performed diagonal tests on reduced scale wallets strengthened with Glass Fibre Reinforced Polymer (GFRP) rods and Glass Fibre Fabric (GFF) sheets. Vasconcelos et al. [8] also presented a solution for strengthening of timber frame walls with glued FRP sheets in some of the connections of the walls in order to assess the influence of this technique on the lateral resistance and lateral strength. Gonçalves et al. [9] have performed in-plane cyclic tests on timber frame walls retrofitted with steel plates, reinforced rendering and dampers applied on diagonal bracers.

More relevant information is available on retrofitting techniques for traditional timber connections [10] [11], which are of great importance for the strengthening of traditional walls, since strengthening of timber frame walls is almost reduced to the strengthening of the connections. However, the implementation of the retrofitting solutions in the wall is not a well-covered topic.

In the scope of the strengthening of structural elements an innovative technique that has been exploited with distinct types of materials, namely structural timber beams, is the near surface mounted (NSM) technique. Examples can be found in practice in the rehabilitation of traditional timber floors [5], using both steel rods or bars and FRP elements, or in experimental results on timber and glulam beams tested in bending [12] [13] [14]. This type of strengthening is particularly efficient in bending, since it increases the bending strength of the timber elements, allowing greater deformations without failure. The efficiency of this retrofitting technique has also been confirmed by its use in reinforced concrete elements [15] [16] for flexural and shear strengthening.

Taking into account the examples encountered in literature about the use of the near surface mounted technique, it was decided to use a similar retrofitting technique in timber frame walls by using steel bars instead of FRP at the connections. The idea was to combine the traditional retrofitting material in timber structures such as steel and an innovative technique regarding its application to the walls. The concentration of the retrofitting at the connections is justified by previous experimental results obtained on timber frame walls subjected to cyclic lateral loads. In fact, the major damage was observed at the connections and the deformation of the walls is clearly controlled by the deformation of the connections [6] [17]. 
Thus, the main aim of the present work was the assessment of the effectiveness of applying the near surface mounted technique as a retrofitting method to timber frame walls for the improvement of the overall mechanical performance, namely in terms of lateral stiffness, lateral resistance, ductility and energy dissipation. For this, an experimental campaign was designed based on lateral cyclic tests of timber frame walls with and without brick masonry infill retrofitted with near surface mounted steel flat bars. Besides the description of the retrofitting techniques, the paper focuses on the presentation and detailed discussion of the results on the influence of the retrofitting in the mechanical performance of the walls.

\section{Experimental campaign performed on timber frame walls}

The experimental campaign for the evaluation of the effectiveness of the retrofitting of timber frame walls by using the NSM technique was designed based on static cyclic tests on real scale walls characteristic of ancient Pombalino buildings. For this, different typologies were considered before retrofitting, namely timber fame walls filled with brick masonry, timber frame walls with lath and plaster infill and timber frame walls without any infill material [6]. After testing the walls in an unreinforced condition, these same walls were repaired and then retrofitted with different techniques. This paper focuses on the use of the NSM technique. The significance of the present study relates to the great importance of obtaining an insight on the performance of the retrofitting techniques for seismic loads here simply represented by static cyclic loads in view of gathering knowledge to better act in rehabilitation purposes. In effect, no real information is available on the behaviour of such structural elements after their rehabilitation, even though many buildings have been retrofitted.

Only recently experimental work has been carried out on traditional timber frame walls considering different wall types from different countries [17-23], considering their original configuration. Furthermore, many studies concern strengthening solutions of traditional carpentry joints, particularly for roofs [10] [11], without analysing the behaviour of the whole retrofitted structural element. 


\subsection{Walls specimens}

Different kind of materials could be used in the construction of the timber frame walls, both in terms of timber and in terms of masonry, but it was decided to use materials adopted in the Portuguese tradition, i.e. maritime pine (Pinus pinaster) and solid bricks for masonry.

The timber frame of the walls was built in a local carpentry specialized in rehabilitation projects. Real scale dimensions for the wall specimens were considered. Thus, the sectional dimensions of all the members and the size of the cells were decided according to the dimensions of existing buildings found in literature [1]. The top and bottom beams have a cross section of $16 \times 12 \mathrm{~cm}^{2}$ and all the other members a cross section of $8 \times 12 \mathrm{~cm}^{2}$. The total width of the wall is $2.42 \mathrm{~m}$ and the total height $2.36 \mathrm{~m}$, resulting in a height to length ratio of approximately 1.0 . The cells are $86 \mathrm{~cm}$ wide and $84 \mathrm{~cm}$ high.

The connections of the main frame are all half-lap connections, as well as the connections between each two diagonals, whereas the connection between the main frame and the diagonals is made through contact (Fig. 1). In every connection a nail was inserted. The nails used in the half-lap connections were $10 \mathrm{~cm}$ long, while those connecting the diagonals to the main frame were $15 \mathrm{~cm}$ long. The nails had a square cross section of 4 and $6 \mathrm{~mm}$ side respectively.

Part of the timber frames built was filled with solid brick masonry, a kind of infill which is of common use in traditional timber frame walls. The masonry pattern was suggested by a Portuguese company from Lisbon which specializes in the rehabilitation of Pombalino buildings. The masonry pattern consists of double leaf masonry with transversal series of bricks every two rows of horizontal double leaf masonry, as detailed in Fig. 2 and further described in [6].

\subsection{Retrofitting with NSM steel flat plates}

\subsubsection{Description of the retrofitting schemes}

After analysing the damages found in unreinforced timber frame walls submitted to in-plane cyclic tests [6], an innovative strengthening technique was adopted, consisting of applying steel flat bars in the connections inserted by applying the near surface mounted technique (NSM), see Fig. 3a. The bars had a cross-sectional dimension of $8 \times 20 \mathrm{~mm}^{2}$. This technique can be seen as an 
alternative technique to the addition of connectors (bolts and nails), glued steel plates or steel plates fixed with screws. This intervention is potentially invisible, but not removable. As aforementioned, this technique has been adopted with much success by using fibre reinforced polymers (FRP) in the retrofitting of reinforced concrete elements, namely columns, beams and slabs [15] [24]. The intention and innovation is to use the same technique with a more traditional material (steel) and apply it to vertical elements for seismic retrofitting.

From the results obtained during tests on unreinforced timber frame walls, it was seen that the major damage concentrates at the connections. As can be seen in Fig. 3b, connections opened during the tests, crushed and failed [17]. Therefore, it was decided to define distinct retrofitting configurations at the connections of the walls. Notice that, as performed for the unreinforced test [17], the walls were tested considering two levels of vertical pre-compression (25kN/post and $50 \mathrm{kN} /$ post), which will be discussed later.

Apart from the NSM technique, other two options were tested, specifically bolts and steel plates [25]. Here, a small summary is presented in order to be able to better compare the efficiency of different retrofitting techniques. Individual bolts were applied to the nine main half-lap connections of timber frame walls (Fig. 4a), linking the posts to the beams. This technique did not offer additional strength to the walls, but it improved their post-peak behaviour [25].

Timber frame walls with masonry infill were also retrofitted with custom steel plates, with a star shape (Fig. 4b), linking the diagonals to the post and beam of the connection. This solution proved to greatly stiffen the wall, which gained considerably in terms of load capacity. Even the failure of the wall changed, as failure moved to the half-lap connection of the diagonals. The behaviour of the walls was characterized by some out-of-plane movement. Both retrofitting techniques were able to improve the shear response of the walls [25].

Finally, timber frame walls without infill were retrofitted using commercial steel plates [27], considering two configurations: (1) linking the diagonals to the main members of the wall; (2) not linking the diagonals, but only the posts to the beams (Fig. 4c). The first configuration resulted in a great increase of stiffness for the walls, which led to important out-of-plane movements [25]. The gain in terms of strength was great, but the solution proved to be too stiff for a wall without infill, 
resulting in a loss of ductility. The second solution was able to guarantee better results, giving a good increase in terms of stiffness and load capacity, without compromising the displacement capacity of the wall.

Seeing the advantages and disadvantages of the previous retrofitting techniques, a NSM strengthening intervention was chosen in order to obtain the same gains of the steel plates interventions, but simultaneously avoiding the out-of-plane mechanisms developed, which can prevent the gain in post-peak deformations. Considering what was learned from the tests with steel plates strengthening [25], it was decided to apply this kind of strengthening only at the main halflap connections, i.e. to the connections between vertical posts and horizontal beams, without linking the diagonals.

According to what is shown in Fig. 4, changes were made in the configuration of the NSM steel bars for the walls tested adopting a trial-and-error approach. The first disposition of bars was chosen considering than the main damages were observed at the mid-height connections and at the bottom connections. To guarantee a sufficient anchorage length, the bars embedded in the bottom connections were bent at 90 degrees, on the side of the wall where the posts are discontinuous, i.e. the beams overlap them (Fig. 5a). To achieve this, they had to be cut at middepth, bent and the cut was filled with welding. For all the connections at the bottom and midheight of the wall, two parallel bars were embedded in the posts and in the beams on the side where they were discontinuous, to avoid the opening of the connections, and one bar was embedded on the opposite side, where the posts and beams were continuous, to improve the resistance of the material. This disposition was tested for timber frame walls with masonry infill and a pre-compression load of $25 \mathrm{kN}$ on each post (RIW25_S). A detailed explanation of the vertical loads applied is presented in section 2.5.

After analysing the results, it was chosen to decrease the number of steel flat bars for the timber frame wall tested with the higher vertical load level (wall RIW50_S, Fig. 5b). Only one bar was inserted in each connection on each side of the wall in the direction where the element was discontinuous, i.e. where the overlapping occurred. 
It is to be pointed out that, in order to save material, the connection at the top beam in the middle position was not strengthened, because it was thought that the confinement given by the test setup made it superfluous.

For timber frame walls without infill (Fig. 5c), since the confinement given by the infill is not present, it was decided to insert in each connection cross-shaped bars welded together with a notched connection in the middle. The bottom connections were strengthened with commercial steel plates, similarly to what done for the second solution for timber frame walls with masonry infill. This configuration was adopted for both vertical load levels. For detailed information of the geometry of the retrofitting, see [6].

The following parameters were taken into account when designing the interventions mentioned above: (1) cross-sectional dimensions of timber elements involved. Limitations on the minimum distances from the borders should be followed for the cuts; (2) presence of knots or of pre-existing drying fissures. Slots should not be made near knots, since they could weaken this zone. Moreover, important fissures should be filled; (3) tensile strength of steel flat bars. Attention should be paid to the type of steel flat bars used in order to guarantee a sufficient tensile strength to the connection; (4) bond strength between steel flat bars and structural glue and between structural glue and component material. The bond between the materials should be investigated in order to avoid early failure due to debonding [12]; (5) anchorage length.

For NSM techniques Eurocode 5 [26] does not apply directly, but usually the application of strengthening with this technique is based on experimental results from literature. NSM strengthening has been applied to timber only in recent years. Studies have been performed by Jorge [12], studying the bond behaviour between glulam and FRP and then applying FRP strips with the NSM technique to continuous double span glulam slabs and testing them. From the analysis of the tests, the author suggested that an anchorage length of 15 times the diameter should be used. The same anchorage length is suggested by other authors. For FRP strips, good performances were found for bond length of 7.5 times the height of the strip [16] for concrete structures. 
For the bars used, it was decided to adopt an anchorage length of at least $20 \mathrm{~cm}$ from the half-lap connection [6]. In order to have sufficient strength, a high performance steel was used, CK45, which will be further analysed below. The choice of the cross-sectional dimension of the flat bars was made considering an expected maximum resistance for the walls, which was estimated at $175 \mathrm{kN}$.

\subsubsection{Description of the retrofitting technology}

Since the walls intended to be tested in the retrofitted condition were the same ones already tested in the unreinforced condition, before retrofitting the walls, the heavier damages encountered by the walls during the previous unreinforced tests were repaired. Masonry had little damage during the unreinforced tests, but still mortar cracked and some bricks fell off. To reinstate masonry to its almost initial condition, a natural hydraulic binder was used (PROMPT [27]), characterized by a good adhesion to all building materials and by a fast setting, so the repair of masonry was done immediately prior to testing.

Another damage encountered was the out-of-plane opening of the half-lap connections, as the nails were pulled out. The opened connections were closed using a bar clamp.

Infill walls tested with the higher vertical load encountered damage in the central post at the central connection, which crushed due to the shear effect of the diagonals. It was decided to repair the post by gluing a prosthesis. The damaged part of the central post had to be removed until healthy timber was encountered and an appropriately cut wood piece was glued using a structural timber glue (Mapei Mapewood Paste 140 [28]). In the case of timber frame walls without infill, damages were too extensive, so it was decided to substitute the whole central post.

In order to perform the retrofitting, slots were opened in the elements with a plunge router, having a width of $12 \mathrm{~mm}$ and a depth of $23 \mathrm{~mm}$ to accommodate the flat bars with a section of $8 \times 20 \mathrm{~mm}^{2}$; at least $1.5 \mathrm{~mm}$ on each side of the bar was allowed, so that the glue can adhere well. The cuts were then cleaned with compressed air and filled with structural timber glue [28] (Fig. 6a), being then the steel flat bars inserted (Fig. 6b). Additional glue was added if necessary to completely fill the slots while excessive glue was cleaned in order to clean final appearance (Fig. 6c) for the connection. To achieve the maximum strength, the glue had to cure for 7 days. 


\subsection{Material properties}

In order to be able to better assess the behaviour of the walls during the cyclic tests, all materials have been characterized, namely wood, mortar, masonry infill, structural timber glue and steel flat bars. The results concerning wood, mortar, bricks and masonry are reported in [17] and [25]. Additionally, structural timber glue and steel flat bars have been tested in tension according to standard BS EN 10002-1 [29]. As already mentioned, the structural timber glue used is MAPEI Mapewood Paste 140, which is a thixotropic epoxy adhesive for the restoration of timber structural elements [28]. According to its technical data sheet, the glue has a tensile strength of $18 \mathrm{MPa}, \mathrm{a}$ flexural strength of $30 \mathrm{MPa}$ and a flexural modulus of elasticity of $4 \mathrm{GPa}$. It reaches complete hardening in 7 days.

To retrofit the walls, steel flat bars of CK45 steel were used, which presented a yield strength of 420.8MPa (c.o.v. 2.05\%), an ultimate strength of 672.9MPa (c.o.v. 0.43\%) and a Young modulus of $194107 \mathrm{MPa}$ (c.o.v. $1.30 \%$ ). The percentage of elongation of the bars after fracture was of $16.1 \%$ (c.o.v. 5.06\%). The structural timber glue used had a tensile strength of $13.99 \mathrm{MPa}$ (c.o.v. 16.23\%), a value lower than what indicated in the technical data sheets. From visual inspection performed on the walls after the tests, when the connections were cut in different sections, perfect adherence was found between the steel bars and the glue and between glue and wood, meaning that if adequate anchorage length is found, no debonding should occur between bond material and steel flat bars.

Considering the results found and the fact that the bars had a section of $8 \times 20 \mathrm{~mm}^{2}$, the ultimate tensile force that they could withstand was of $108 \mathrm{kN}$ per bar.

\subsection{Test setup and instrumentation}

The tests were performed in the Structural Laboratory from University of Minho by using the setup illustrated in Fig. 7, the same setup used for the tests performed on unreinforced walls [17]. The application of the vertical load was done by means of vertical hydraulic actuators applied directly on the three posts of the walls and connected to the bottom beam through steel rods which 
connected the actuators to a hinge welded in the bottom beam, so that the actuators were able to follow the horizontal movement of the wall.

The horizontal displacement was applied to the top timber beam through a hydraulic servo-actuator with a maximum capacity in terms of displacement and load of $200 \mathrm{~mm}$ and $250 \mathrm{kN}$ respectively. The actuator was connected by means of a 3-D hinge to the reaction wall and by means of a twodimensional hinge to the wall specimen. The top beam of the wall was confined by two steel plates connected through sufficiently stiff steel rods so that cyclic displacements could be imposed to the top of the wall. The bottom timber beam was connected to the bottom steel profile in 6 points and it was confined laterally in order to prevent any kind of movement in this element.

A structure was implemented to prevent out-of-plane displacements, creating a guide for the top of the wall as described in [6].

All the walls were instrumented with linear voltage displacement transducers (LVDTs), placed in strategic positions to capture the global and local behaviour of the walls. The horizontal displacements at the top and mid height beam were measured on both sides of the wall. Two LVDTs were placed on the two sides of the walls at mid height to measure the horizontal in-plane displacement of the central beam on the two sides. The vertical uplift of the three bottom half-lap connections was monitored (see Fig. 8). The displacement of the diagonals was measured by LVDTs DF and DB. The local opening of the half-lap and nailed connections in different positions of the walls was measured, at mid height, considering the opening of both half-lap connections and simple nailed connections, see Fig. 8.

In order to understand the efficiency of the strengthening materials and their actual participation during the tests, strain gauges were positioned in strategic positions, particularly on the flat bars and on the steel plates. Strain gauges were applied in the direction where the timber element was discontinuous (Fig. 9). As an example, strain gauge MV was applied on the bar in the vertical direction on the side where the post was discontinuous and the bar effectively linked the post to the beam, while strain gauge MHR was applied to the same connection on the opposite side where the beam was discontinuous and on the right side of the half-lap connection. 
Moreover, strain gauges were applied to the timber post (TH and TL) in order to record the strains in this element.

\subsection{Vertical loading and cyclic procedure}

Two different pre-compression load levels were considered, namely $25 \mathrm{kN} /$ post and $50 \mathrm{kN} /$ post. The level of $25 \mathrm{kN} /$ post resulted from the calculation of the dead and live vertical loads corresponding to three floors of the typical buildings according to Eurocode 1 [30]. For additional information, see [6]. The application of a different vertical load level of about $50 \mathrm{kN} /$ post aimed at assessing the influence of this variable on the lateral response, considering also that it is possible that due the fact that timber frame buildings have experienced a great rehabilitation effort in the last years, their structure and use have been changed, being feasible that additional vertical loads can act on this type of walls. Note that originally these walls are intended to act mainly as shear walls. Therefore, it is convenient to study the effect of additional loads on the structural element.

The cyclic procedure adopted during the tests was based on standard ISO 21581 [31]. In order to better capture the highly non-linear behaviour of the walls, additional steps were added in the procedure, considering an increment in the applied displacement of $10 \%$ of the ultimate one (see Fig. 10).

Two different test speeds were adopted: one for displacements up to $10 \%$ of the maximum displacement (namely $0,05 \mathrm{~mm} / \mathrm{s}$ ) and one for the remaining displacement levels (namely $0,35 \mathrm{~mm} / \mathrm{s}$ ). The first speed is the one adopted in the monotonic test, which meets standard requirements [31]. The second one was adopted based on a balance between low speed and tests duration, since according to the standard, cyclic tests should have the same speed of monotonic ones.

Due to limitations of the test equipment, the application of the displacement was made with a sinusoidal relationship for the cycles, and not a linear one, so the speed reported is a mean velocity. From the results of a preliminary test it was seen that no difference was observed in the response of the wall between this loading procedure adopted and a linear one.

In total, four retrofitted walls were tested, distributed in two distinct groups, see Table 1, according to the type of infill: (1) walls named as RIW with brick masonry infill; (2) walls named as RTW, in 
which no infill was considered, i.e. timber frame walls. The number 25 or 50 used in each designation is associated to the vertical load applied in each post of the walls, $25 \mathrm{kN}$ and $50 \mathrm{kN}$ respectively.

For each typology only one specimen was tested. This choice was made considering the scarce availability of specimens as well as the very low scatter on the results obtained in the unreinforced tests [6]. Therefore, based on this it is considered to be reasonable to have a single test as representative, once the same precautions and the same conditions were adopted in the retrofitted tests.

\section{Analysis of test results}

Quasi-static cyclic tests can simulate in a simple way the seismic loading and provide important information on the overall mechanical behaviour and shear resistance of walls subjected to lateral loads. The analysis and discussion of results is divided into three parts, namely: (1) discussion of the typical force-displacements hysteresis diagrams; (2) discussion of the main deformation features and typical failure modes; (3) assessment of seismic performance indicators. A detailed overview of the cyclic behaviour of unreinforced timber frame walls and on the influence of distinct filling material in the mechanical behaviour can be found in [6].

\subsection{Typical hysteretic diagrams and damage patterns}

In this section the hysteretic diagrams of the retrofitted walls tested are presented, together with the vertical uplift of the bottom connections, in order to better understand the behaviour of the walls. Unreinforced timber frame walls with masonry infill exhibited a strong flexural behaviour when tested with the lower vertical pre-compression load, characterized by rocking of the walls and uplifting of the vertical posts. This vertical uplift in particular created a horizontal plateau in the unloading branch while the bottom connections were closing [17]. The walls tested for the higher pre-compression load level presented a composite flexural-shear mechanism [17]. This behaviour is to a great extent the result of the weak connection of the posts to the bottom beam, which is made through a single nail, similarly to what can be seen in the existing walls [1] [5]. Besides, from 
previous experimental results [17] it is clear that the presence of brick masonry infill also contributes to the confinement of the connections, which limits their deformability and promotes the rocking of the entire wall when the vertical pre-compression load is low. In case of timber frame walls without infill, the shear resisting mechanism is considerably much prevailing in the response under lateral loads, which is attributed to the freedom of the connection to deform and the more stressed timber elements, namely the diagonals [17].

In qualitative terms, it is observed that the presence of NSM steel flat bars enhances the lateral behaviour of timber frame walls with masonry infill, with the improvement on the lateral resistance of $62 \%$ and $30 \%$ for the walls submitted to the lower (RIW25_S) and higher (RIW50_S) precompression load levels respectively, see Fig. 11a,b, when compared to the corresponding unreinforced tests (UIW25 and UIW50). The lower increase for walls subjected to the higher vertical load is to be attributed to the lower amount of retrofitting used.

In case of wall RIW25_S, two phases can be identified in relation to the predominant resisting mechanism. The first phase is characterised by a predominant shear resisting mechanism before the failure of the bottom connections due to failure of the welding applied to the steel flat bars associated to excessive tensile stresses developed at the bottom connections, see Fig 12a. As a consequence of this failure, the behaviour of the wall exhibited a rocking behaviour characterized by the S-shape of the curve (Fig. 11a), similarly to what happens with unreinforced walls [17]. It is interesting to notice that in the second phase, after failure, the force-displacement diagram is practically coincident with the one recorded for unreinforced wall. In fact, after failure of the bottom connections the remaining steel bars are ineffective and almost no contribution to the cyclic response is recorded. The failure of the bottom connections led to the natural increase of the vertical uplift, see Fig 11a. The anchorage configuration adopted for the NSM steel bars revealed not to be adequate resulting in the opening of horizontal cracks in the bottom beams due to tensile stresses developed in the direction perpendicular to the grain, in the bent part.

To prevent such a premature failure of the bottom connections, it was decided to use commercial steel plates at the base for wall RIW50_S. Moreover, in this case only one plane of NSM steel bars was considered by applying the steel flat bars in one direction on each side of 
the wall (see Fig. 5b). This choice was made due to the confinement given by the infill to the connections, which prevents sudden ruptures. The shear resisting mechanism prevailed in the lateral response of wall RIW50_S, which was particularly evident by the shape of the hysteretic diagram and from the limited vertical uplift of the posts (Fig. 11b). In this case only a minimal plateau in correspondence to the closing of the connections in the unloading branch was recorded when compared to the unreinforced wall. Due to the strengthening, the wall was able to deform without experiencing ruptures or severe crushing in the connections. In both infill walls, damages were observed in the masonry infill, with cracking, detachment of masonry from the main frame and out-of-plane rotation of the masonry blocks. The damages were concentrated in the bottom half of the wall, as happened in unreinforced walls [17], but they propagated even in the upper part of the walls.

For timber frame walls without infill, given the absence of the confining effect of the brick masonry and the predominant shear resisting mechanism observed in unreinforced walls [6], accompanied by the higher level of deformation of the connections it was decided to strengthen all connections applying the NSM steel flat bars both horizontally and vertically at the main half-lap connections. From the comparison between unreinforced (UTW) and retrofitted timber frame walls (Fig. 11c,d) it is clearly visible a considerable improvement of the lateral response, with the increase on the lateral resistance of about $197 \%$ and of $64 \%$ for the retrofitted walls submitted to the lowest and highest levels of pre-compression respectively when compared to the unreinforced condition. However, a reduction on the ultimate displacement capacity was also observed being of $12 \%$ in case of the wall RTW25_S and of 6\% in case of the wall RTW50_S. It should be pointed out that, for the last loading steps, the walls experienced a small out-of-plane component, which should be associated to the high level of stresses to which they were subjected, reducing their ultimate displacement capacity.

A remark should be made in relation to the increase percentage on the cyclic lateral resistance of wall RTW50_S. In fact, it was observed that in no case the walls presented severe damage both at the connections and timber elements. Due to this, wall RTW50_S was submitted to a monotonic test after the cyclic test in order to characterize the failure mechanism. For this test, it was 
observed the failure of the central connection, see Fig $12 \mathrm{~b}$, associated to the failure of the bar at the welding and further propagation of cracking in the wood.

The lateral resistance obtained of $179 \mathrm{kN}$ was $121 \%$ higher than the one recorded in the unreinforced timber frame wall, which confirms that the increase on the lateral resistance recorded in the cyclic test did not mobilize all the contribution of the steel flat bars and does not correspond to the failure configuration of the wall. The lateral displacement corresponding to the failure of the wall was of about $89.36 \mathrm{~mm}$.

In both timber frame walls, the lateral response of the walls is governed by the resisting shear mechanism, even if the uplifting at the bottom connections was still present. A difference between the two walls is observed in the unloading branch, since RTW50_S wall presents a non-smooth unloading branch, even though the vertical uplift was lower. This could be due to greater difficulty in the recovery of the uplift deformations due to the higher friction resistance associated to the higher levels of stress imposed in the posts, as witnessed by the higher strains registered in this wall.

Pinching characterised the response of all walls strengthened with steel flat bars, but the effect was more evident for timber frame walls without infill, similarly to what occurred for walls retrofitted with steel plates [20]. It appears that pinching manifests itself more when the timber elements have more deformation capacity due to the absence of infill.

By comparing the improvement of the lateral strength between timber frame walls with and without infill, it is observed that the retrofitting with NSM steel flat bars proved to be more effective for walls without infill. This should be associated to the absence of infill allowing the timber frame to deform more and develop a more predominant shear resisting mechanism. This result, however, does not invalidate the technique for infill walls, particularly if a system where infill has a small resistance and stiffness is considered.

\subsection{Detailed analysis of the deformational features of the walls}

Besides the uplift of the post analysed previously, some other deformational features are also analysed here in order to get a better insight on the lateral behaviour of the walls. 
From the typical movement of the diagonals (Fig. 13) and comparison between unreinforced and retrofitted walls, it is possible to understand the stiffening effect that the strengthening technique has on the walls. In spite of the diagonals being submitted to higher levels of compressive stresses inducing higher shear stresses at the central connections, given that the lateral resistance is considerably higher than in case of unreinforced walls, low levels of damage in the connections were observed. This retrofitting technique improved thus the shear resistance of the connections by preventing their crushing as it was observed in unreinforced walls [17]. In any case, the diagonal displacements are clearly limited when compared to the ones observed in the unreinforced walls. This is particularly relevant in case of timber frame walls without infill, as it presents more than the double of the diagonal displacements. Only after failure of the central connections due to the strengthening failure during the monotonic testing of the timber frame wall submitted to the highest level of pre-compression, see Fig. 13b, the diagonals reached high values of displacement.

The same conclusions can be drawn from the analysis of the horizontal displacement at mid height of the wall, when comparing the same displacement observed in retrofitted and unreinforced walls, see Fig. 14. For the retrofitting solution adopted, the displacement on the two sides of the wall are symmetrical, with only a slight asymmetry at mid height for higher deformations.

The relative vertical and horizontal displacement of the diagonal in relation to the main frame is low due to the higher confining effect of the NSM steel flat bars in the walls, particularly in case of infill walls (Fig. 15a). Similarly to what happened in unreinforced walls, retrofitted timber frame walls without infill present a higher level of detachment, even if it is $75 \%$ lower than what observed in case of unreinforced walls [17], see Fig. 15b.

To understand the efficiency of the strengthening techniques adopted, in particular to understand the level of activation of the element applied, strain gauges were applied to the steel flat bars. Steel flat bars applied to both types of walls registered high values of strain, reaching values beyond the yielding point. For infill walls (Fig. 16a), the most stressed bars were the ones embedded in the half-lap connection where the element was discontinuous; in this case the horizontal bar was linking the beam to the post. Both vertical and horizontal bars reached strains of $5 \%$, confirming 
that the steel flat bars are in the plastic regime. In timber frame walls (Fig. 16b,c), NSM steel flat bars at the central connections exhibited the highest strains, attaining values of $6 \%$. Lower strains were recorded in the steel bars located at the lateral posts reaching values of $2 \%$.

With the deformations reached, the approximate strength estimated in the bars for deformation of $6 \%$ was of $627 \mathrm{MPa}$, a value $50 \%$ higher than the yield strength. In Fig. $17 \mathrm{a}, \mathrm{b}$ it is possible to observe the deformation of the bars in both types of walls. For both wall typologies, the bars deformed in the plastic regime.

\subsection{Quantitative analysis - seismic performance indexes}

In the seismic design of new timber structures or in the rehabilitation of existing structures, including historic timber frame walls, the study of the seismic performance is of paramount importance. In order to better understand the complex response of timber structures, some parameters can be used to assess the efficacy of the solution. Parameters such as ductility, energy dissipation, overall cyclic stiffness, equivalent viscous damping ratio and lateral drifts characterize the behaviour of timber shear walls and are helpful in evaluating the performance of a structure under cyclic loading and evaluate also the effectiveness of the retrofitting technique. In this section, the main seismic performance indexes are presented for the walls previously analysed and a comparison is made with the unreinforced walls.

\subsubsection{Obtaining the bi-linear idealized diagrams}

Aiming at obtaining the equivalent bilinear diagrams, which are a perfectly elasto-plastic representation of the actual response of the wall specimens, the envelope curves for each wall tested were defined, see Fig. 18. The envelope curves are defined as the curve connecting the points of maximum load in the hysteresis plot in each displacement level [31].

The initial stiffness offered by the NSM solution is similar for both infill and timber frame walls, but the ultimate capacity reached is higher for walls without infill, see Fig 18, mainly due to the different mechanisms developing in the two kinds of walls. In infill walls the flexural behaviour predominates and consequently the strengthening of the bottom connections is of paramount importance so that the uplift of the walls can be avoided. Notice that if flexural/rocking predominates, the deformations 
of the remaining connections are limited, which contribute for lower efficiency of NSM steel flat bars, given that they are not exploited. In timber frame walls the connections present a higher degree of mobility, meaning that the reinforcement introduced at the connections is able to contribute more for the lateral resistance. In case of RIW25_S, the capacity of the wall was influenced by the early failure of the flat bar applied to the bottom connection. It should be stressed that in case of an infill with lower stiffness and resistance, this behaviour would be less emphasized.

Notice that in case of walls without infill, the influence of the vertical load becomes practically insignificant.

The bi-linear idealization of the envelopes is presented in Fig.19 for the unreinforced and retrofitted walls under study. Only positive values are shown, since it was decided to take the positive displacements of the envelope for the calculation of seismic performance parameters. The method used for the determination of the bi-linear diagrams was suggested by Tomaževic [32], considering the failure load as $80 \%$ of the maximum load and calculating the yield displacement from the equivalence of the areas. It should be pointed out that for the majority of the walls, the ultimate displacement corresponds to the maximum one obtained experimentally, since only one wall lost more than $20 \%$ of the maximum load in the degradation process (namely wall RIW25_S). Therefore, the ultimate displacement corresponds to the displacement reached in the last cycle imposed to the walls.

\subsubsection{Evaluation of initial stiffness and stiffness degradation}

According to European Standard ISO DIS 21581 [26], the lateral stiffness of the walls, $K_{1, i n+}$, may be calculated according to eq. 1 :

$$
K_{1, \text { in }}=\frac{0,3 F_{\max }}{\delta_{40 \% F_{\max }}-\delta_{10 \% F_{\max }}}
$$

where $\delta_{40 \% F_{\max }}$ and $\delta_{10 \% F_{\max }}$ are the displacement values obtained in the envelope curve at $40 \%$ and $10 \%$ of the maximum load $\left(F_{\max }\right)$ respectively.

The consideration of the initial displacement corresponding to $10 \%$ of the maximum force should be associated to the need of overcoming some type of initial nonlinearity. It should be noticed that 
in this case of traditional timber frame walls, considerable nonlinear behaviour to very small values of lateral drift were recorded [17] [25]. Therefore, in this work it was also decided to calculate the secant stiffness taking into account the origin and the point corresponding to $40 \%$ of the maximum load $\left(\mathrm{K}_{1, \mathrm{~s}_{+}}\right)$, aiming at a comparison with the values obtained for $K_{1, i n+}$. All values of stiffness were calculated for the first cycle.

The values of secant stiffness, $\mathrm{K}_{1, \mathrm{in}+}$, and $\mathrm{K}_{1, \mathrm{~s}+}$, are shown in Table 2 . It is observed that no significant differences were found between the initial stiffness values calculated by both procedures.

As happened for other retrofitting techniques [25], the application of the NSM steel flat bars leads to higher values of initial stiffness than the ones recorded for unreinforced walls [17].

The NSM steel flat bars increase clearly the initial stiffness of the walls for the lower precompression load (25kN/post), by about $38 \%$ for infill walls and by $96 \%$ for timber frame walls without infill. When the walls are submitted to the vertical pre-compression load of $50 \mathrm{kN} /$ post, the effect of the NSM steel flat bars on the stiffness is not the same. In fact, almost no changes can be considered; infill walls decreased their initial stiffness, due to the fact that fewer bars were inserted. The timber frame wall without infill increased its initial stiffness by $28 \%$, while the value of secant stiffness calculated with the second method remained unaltered.

The difference on the improvement of the stiffness due to retrofitting among the walls should be associated to: (1) the stiffening contribution of brick masonry to timber frame walls and the predominance of the flexural behaviour results; (2) the fact that in case of the infill walls submitted to a pre-compression load of $50 \mathrm{kN} /$ post, the configuration adopted for the NSM steel flat bars resulted in a lower amount of steel bars; (3) the higher effectiveness of NSM steel flat bars to increase the shear stiffness of the walls; (4) the higher deformation capacity of timber frame walls without infill, that present lower values of stiffness when unreinforced.

The improvement of the initial stiffness given by NSM steel flat bars appears to be in line with results achieved by past researches. According to Vasconcelos et al. [8], the strengthening of timber frame walls by applying GFRP sheets at the connection increased clearly their initial stiffness. 
The variation of cyclic stiffness for increasing lateral drifts is presented in Fig. 20. Cyclic stiffness was calculated for each cycle considering the average of the slopes of the line connecting the origin and the two points of loading corresponding to the maximum (positive and negative) displacements. Due to the accommodations that occur in the wall for low values of drifts, which relate to the presence of clearances in some connections, cyclic stiffness calculated for drift values lower than $0.15 \%$ is not considered reliable and thus they are not represented here. The lateral drift is calculated as the ratio between the lateral top displacement and the height at which the lateral load is applied. For all walls a considerable decrease on the cyclic stiffness is found for values of drift lower than $0.5 \%$, due to the accommodations in the walls at the beginning of the test. After this stage, the decrease on the stiffness is much lower and should be associated to the cumulative damage developed in the walls. It should be noticed that stiffness degradation is lower in case of the retrofitted timber frame walls without infill for the same lateral drift, which should indicate a better performance of the damage distribution and damage propagations. In fact, it appears that for these walls, the decrease on the cyclic stiffness up to lateral drifts of approximately $0.5 \%$ is followed by an increase up to a lateral drift of $1 \%$; the strengthening does not immediately start working, as the initial values of stiffness are lower and comparable to those of unreinforced timber frame walls [17].

The amount of vertical pre-compression applied has little influence on the cyclic stiffness of the walls. In general, stiffness was higher for walls with a higher pre-compression level, but the difference was minimal.

It has to be pointed out how, once wall RIW25_S failed at the bottom connections, its behaviour became that of an unreinforced wall; even the values of stiffness were the same as what registered in unreinforced walls.

\subsubsection{Evaluation of ductility}

Ductility is an important factor for the evaluation of the seismic behaviour of structures in seismic regions, as it is directly related to the ability of the structure to deform nonlinearly without significant loss of strength. Displacement ductility is defined here as the ratio between the ultimate displacement $\left(d_{u}\right)$ and the yield displacement $\left(d_{y}\right)$ defined in the equivalent bilinear diagram 
(Section 3.3.1). Ductility $\mu_{1}$ was calculated using the values of secant stiffness calculated above considering the slope of the curve between the origin and $40 \%$ of the maximum load. Only the portion of the bilinear curve corresponding to positive values of displacement was considered. As seen from Table 3, it appears that a reduction of ductility is found for retrofitted walls. Nevertheless, it should be stressed that the limitation of the results obtained in this work is related to the fact that the values of the maximum lateral displacement obtained for the retrofitted walls did not effectively correspond to the failure of the walls and only moderate levels of damage were found. This can justify the lower values of ductility found for the retrofitted walls, when compared to the unreinforced walls, see Table 3 . In particular, it is seen that the decrease on the ductility is related to the relative increase of stiffness and lateral resistance promoted by retrofitting. In fact, higher values of elastic displacement are found for stiff and high resistant walls, which is particularly relevant in case of timber frame walls. Taking into account that the real maximum imposed displacements were not attained, due to the limited damage found, the trend for the decrease on the ductility of retrofitted walls should be seen with care. At least, the differences should not be as high, if the collapse state of the retrofitted walls was attained.

As already mentioned, only wall RIW25_S had a loss of strength higher than $20 \%$.

For these reasons, the values of ductility could increase if the tests could go further in terms of lateral drifts, as it believed that the walls would assure higher levels of lateral drift. Nevertheless, it was decided to provide the ductility of the walls, even if it should be viewed as indicative in some cases. For example, wall RIW50_S experienced a strength loss of 7\% and wall RTW25_S of 0.4\%. In any case, if the lateral drifts are considered, it is seen that the retrofitted walls are able to attain the same lateral drifts with considerably lower damage, which represents a great advantage of the retrofitting of the walls.

\subsubsection{Assessment of the ability to dissipate energy}

Besides ductility and lateral drifts, one major parameter used for the assessment of the seismic performance of the seismic behaviour is the ability of a structural element to dissipate energy during cyclic testing. Here, the cumulative energy is considered. The energy dissipated by the walls at each cycle, $E_{D}$, is computed by calculating the area enclosed by the loop in the load- 
displacement diagram and it represents the amount of energy dissipated during the cyclic loading. The energy can be dissipated through friction in the connections, yielding and deformation of the retrofitting steel bars and permanent deformation accumulated in the walls as observed during the tests.

From Fig. 21, it is seen that all retrofitted walls were able to dissipate a higher amount of energy when compared to unreinforced tests. Taking into account that a further lateral displacement could be imposed to the retrofitted walls, the maximum cumulative dissipated energy would be even greater. It is interesting to notice that wall RIW25_S presents good levels of dissipated energy for low to medium lateral drifts, approaching the values of the energy dissipated in the unreinforced walls after the lateral drift of $2.75 \%$ is achieved, which corresponds to the collapse of the bottom connections and the further predominance of a relevant rocking resisting mechanism. This also shows the difference on the dissipation of energy between shear and flexural resisting mechanism already observed by other authors in relation to other types of shear walls [33].

Timber frame walls with masonry infill increased the total dissipated energy by $25 \%$ and $13 \%$ respectively for the lower and higher vertical load level when compared to the unreinforced condition, while timber frame walls without infill increased by $161 \%$ and $52 \%$ respectively.

There is not a clear trend in the dependency on vertical pre-compression and type of wall, as for infill walls the values are similar, while for timber frame walls without infill it would appear that dissipated energy is higher for the wall tested with the lower pre-compression.

\subsubsection{Equivalent viscous damping ratio (EVDR)}

The equivalent viscous damping is a parameter that is highly correlated with the energy dissipation ability. In fact, it is associated to the dissipation of energy during hysteresis. The equivalent viscous damping is calculated according to Magenes and Calvi [35] through eq. 3:

$$
\zeta_{e q}=\frac{E_{d}}{2 \pi\left(E_{e}^{+}+E_{e}^{-}\right)}
$$

where $E_{d}$ is the dissipated hysteretic energy discussed above, $E_{e}{ }^{+}$and $E_{e}{ }^{-}$are the elastic energy for the positive and negative direction of loading of an equivalent viscous system and are calculated at 
the maximum displacement in each loop for the positive and negative direction of loading respectively.

Comparing the results of equivalent viscous damping found for the walls tested (Fig. 22), it is observed that the influence of the vertical pre-compression load is not clear. For both load levels, the values of EVDR were higher for higher values of drift, particularly for the higher precompression level. Retrofitted infill walls presented values of EVDR of approximately 0.12 , while timber frame walls without infill varied between 0.11 and 0.13 , with higher values for the lower precompression. These values corresponds to an increase of the equivalent viscous damping of the retrofitted walls of about $20 \%$ for infill walls, while the increase for timber frame walls without infill was approximately $18 \%$ for the lower vertical load level, while for the higher one the values increased by only $2 \%$. It has to be noticed that for unreinforced walls there was a greater loss in terms of EVDR for higher values of lateral drift. This was due to damage propagation, as it was higher for unreinforced walls, while retrofitted walls encountered lighter damage.

Additionally, comparing the retrofitted and unreinforced walls, it is seen that the retrofitted ones present a lower variation and almost no decrease was recorded after a lateral drift of $1,5 \%$ as happens in unreinforced on the equivalent viscous damping, which should be associated to the more rational distribution of damage. The exception is wall RIW25_S, since the retrofitting failed and therefore the wall reached values of EVDR of the equivalent unreinforced wall. Nonetheless, before failure the wall had reached a stabilized value of EVDR, similarly to the other walls retrofitted with the same technique.

Comparing to similar tests conducted on strengthened concrete block masonry [36], where EVDR is increasing for high values of drift, in the case of timber frame walls the values tend to decrease or reach a constant value. This behaviour is due to pinching, which characterizes timber frame without and, in a smaller scale, with infill, reducing the dissipative capacity of the walls. 


\section{Brief comparison of the seismic performance indexes among distinct retrofitting techniques}

The results of timber frame walls tested with NSM steel flat bars can be compared to the same type of walls strengthened with traditional techniques [25], namely the retrofitting performed with bolts at the connections and steel plates (custom or commercial).

In terms of maximum values (see Table 4), apart from retrofitting performed with bolts, which showed from little to any increase in terms of maximum load capacity, improving only the post peak behaviour of the walls, generally steel plates and NSM steel flat bars retrofitting techniques tended to play a major role in the lateral resistance of the walls submitted to the lower vertical load, reaching an increase in terms of maximum load capacity up to almost $200 \%$. In turn, for the higher vertical load, the increase was not greater than $70 \%$. This phenomenon led to a greater similarity in the behaviour of the wall between the two vertical load levels for each kind of strengthening. For all kind of strengthening, the loss in terms of ultimate displacement (considering that the applied displacement was the same as that which was applied in the unreinforced walls) was usually in the order of $3 \%$ or less.

Concerning the deformation, the walls retrofitted with NSM steel flat bars were deforming less than unreinforced walls and with values similar to those recorded for steel plates retrofitting [25]. Moreover, for the same deformation level, the damage in the walls was considerably less. The stiffening effect of this retrofitting technique can be also observed through the deformations recorded in the single connections, when compared to the ones recorded in unreinforced walls [17]. If for strengthening done with steel plates the connections recorded significant opening, even if the steel plates were effectively confining the connection [25], for the NSM retrofitting technique significant displacements were registered only after complete failure of a connection. The main connections were more rigid, thus did not allow as much movement.

Moreover, though strengthening with NSM steel flat bars resulted in an initial stiffness similar to that given from steel plates [25], being slightly higher for this innovative retrofitting system in timber frame walls, see Table 4, due to the stiffening effect given to the main half-lap connections the 
walls did not experience the same out-of-plane mechanism of the walls strengthened with steel plates since the deformation capacity of the wall was higher, due to the capacity of the diagonal elements to detach from the main frame.

Strengthening with steel flat bars gave a lower dissipative capacity than other types of strengthening [25] for infill walls. On the other hand, this technique guaranteed a slightly higher dissipative capacity for timber frame walls without infill, particularly so for the lower precompression level, even when compared to other retrofitting solutions. It is believed that the energy dissipation performance could be higher for this retrofitting technique when compared to the others. This should be associated to the fact that the total displacement capacity of the walls was not exploited as seen previously, which resulted in lower damages for similar displacement levels. It is supposed that by imposing larger lateral displacement to the retrofitted walls, higher damage could develop leading to higher values of cumulative dissipated energy.

Considering the values of EVDR, the values obtained for the walls retrofitted with this innovative technique are similar to the values encountered for walls strengthened with traditional solutions [25], pointing out that this innovative retrofitting technique could be a comparable alternative when approaching a strengthening problem, particularly if a weak infill is considered for the timber frame wall. Moreover, NSM retrofitting is potentially invisible, an important factor to be taken into consideration if the walls are to be left without plaster.

Lastly, a note should be made concerning the cost of the different retrofitting techniques. While it is clear that retrofitting done with bolts is the cheapest solution (approximately 12€ per wall) and the easiest and less time-consuming to implement, the cost of retrofitting done with steel plates amounts to approximately $130 €$ per wall and it takes one day to retrofit one wall; lastly, retrofitting performed with NSM steel flat bars costs about $100 €$ per wall, therefore less than steel plates, but it takes 8 days to retrofit one wall (1 day for opening the slots and 7 days to apply the glue and let it dry). Moreover, opening the slots requires a precise workmanship.

Therefore, when choosing which retrofitting technique should be used, one should also consider costs and the time required to perform the retrofitting. 


\section{Conclusions}

Aiming at analysing the lateral behaviour of timber frame walls, characteristic of ancient construction in Portugal, and at assessing their seismic behaviour after the application of retrofitting techniques, an experimental campaign was designed based on static cyclic tests. Distinct parameters were considered, namely typology of the wall and vertical pre-compression load. An innovative retrofitting solution was adopted based on steel flat bars embedded in the timber elements adopting the NSM technique.

From the detailed analysis of the experimental results it is possible to conclude that:

- The increase on the vertical pre-compression load does not influence overmuch the behaviour of the retrofitted timber frame walls without infill, while it was significant for infill walls, since the confinement given by the infill hindered the efficiency of the NSM retrofitting solution.

- The NMS steel flat bars retrofitting solution proved to be more appropriate for timber frame walls, since the deformation of the timber elements was not hindered by the infill and the exploitation of the flat bars was greater. Nonetheless, it revealed to be efficient even for infill walls, particularly if a weaker infill is considered, which better follows the deformation of the timber elements, as is the case in many timber frame structures.

- The intervention has the potential of being invisible, which can be of particular interest for historic structures, if aesthetics are an issue.

- The level of energy dissipation by using NSM technique is similar for infill walls and slightly higher in case of timber frame walls without infill, when compared to other retrofitting techniques. It should be noticed that the level of damage found for walls retrofitted with this solution is lower, which should be associated to the possible further exploitation of the lateral displacements. Notice that, contrarily to walls retrofitted with steel plates, walls retrofitted with this technique did not experience significant out-of-plane displacements.

- Based on the simplicity of the retrofitting technology and on the results obtained, it should be stressed that NSM retrofitting technique revealed to be a valid alternative to more traditional retrofitting solutions with the advantage of diminishing the visual impact. Moreover, cost is 


\section{similar to that of steel plates, though a more specialised workmanship or training would be required.}

\section{Acknowledgements}

The authors would like to acknowledge Eng. Filipe Ferreira and A.O.F. (Augusto Oliveira Ferreira \& C Lda.) for their expertise and collaboration in the construction of the wall specimens.

The first author would also like to acknowledge the Portuguese Science and Technology Foundation (FCT) for its financial support through grant SFRH/BD/61908/2009.

The authors would also like to acknowledge the project REABEPA (Structural rehabilitation of masonry walls in old buildings), founded through grant PTDC/ECM/100168/2008, to which part of this research is associated.

\section{References}

[1] Mascarenhas J. A study of the design and construction of buildings in the Pombaline quarter of Lisbon. PhD Thesis, University of Clamorgan; 1996.

[2] Gülhan D, Güney IÖ. The behaviour of traditional building systems against earthquake and its comparison to reinforced concrete frame systems: experiences of Marmara earthquake damage assessment studies in Kocaeli and Sakarya. In: Proceedings of Earthquake-safe: Lessons to be Learned from Traditional Construction, 2000, Istanbul, Turkey

[3] Langenbach R. DON'T TEAR IT DOWN! Preserving the earthquake resistant vernacular architecture of Kashmir. New Delhi: UNESCO; 2009.

[4] Langenbach R. From "Opus Craticium" to the "Chicago Frame": Earthquake-Resistant Traditional Construction. Int J Archit Herit 2007; 1(1):29-59

[5] Cóias V. Structural rehabilitation of old buildings (in Portuguese). Lisbon: ARGUMENTUM, GECoPRA; 2007.

[6] Poletti E. Characterization of the seismic behaviour of traditional timber frame walls. PhD Thesis, University of Minho, Guimarães, Portugal, 2013. http://hdl.handle.net/1822/28845 
[7] Cruz H, Moura J, Saporiti J. The use of FRP in the strengthening of timber-reinforced masonry load-bearing walls. Historical Constructions, P.B. Lourenço, P. Roca (Eds.), Guimarães, 2001.

[8] Vasconcelos G, Poletti E, Salavessa E, Jesus A, Lourenço P, Pilaon P. In-plane shear behaviour of traditional timber walls. Eng Struct 2013; 56: 1028-1048.

[9] Gonçalves A, Ferreira J, Guerreiro L, Branco F. Experimental characterization of Pombalino "frontal" Wall cyclic behaviour. In: Proceedings of the 15th World Conference on Earthquake Engineering (15WCEE), 24-28 September 2012, Lisbon.

[10] Branco J. Influence of the joints stiffness in the monotonic and cyclic behaviour of traditional timber trusses. Assessment of the efficacy of different strengthening techniques. PhD Thesis, University of Minho, Portugal; 2008.

[11] Parisi MA, Piazza M (2002) Seismic behavior and retrofitting of joints in traditional timber roof structures. Soil Dyn Earthq Eng 2002; 22:1183-1191

[12] Jorge MAP. Experimental behavior of glulam-FRP systems. MSc thesis, Department of Civil Engineering, University of Minho; 2010.

[13] Xu Q, Chen JF, Zhu L, Li X, Zhang F. Strengthening timber beams with near surface mounted carbon fiber reinforced polymer rods. In Proceedings of CICE 2012: the 6th International Conference on FRP Composites in Civil Engineering, Rome, Italy, 13-15 June 2012

[14] Juvandes LFP, Barbosa RMT. Bond Analysis of Timber Structures Strengthened with FRP Systems. Strain, 2012; 48:124-135.

[15] Dalfré GM. Flexural and shear strengthening of $R C$ elements. PhD Thesis, University of Minho, Portugal; 2013.

[16] De Lorenzis L, Teng JG. Near-surface mounted FRP reinforcement: An emerging technique for strengthening structures. Composites: Part B, 2007; 38:119-143

[17] Poletti E., Vasconcelos G. Seismic behaviour of traditional timber frame walls: experimental results on unreinforced walls. Bull Earthq Eng, 2014, doi: 10.1007/s10518-014-9650-9;

[18] Aktas YD, Akyüz U, Türer A, Erdil B, Güçhan NS. Seismic resistance evaluation of traditional Ottoman timber-frame Hımıs houses: frame loadings and material tests. Earthq Spectra; 2013. doi:10.1193/011412EQS011M 
[19] Ali A, Schacher T, Ashraf M, Alam B, Naeem A, Ahmad N, Umar M. In-Plane Behavior of the Dhajji-Dewari Structural System (Wooden Braced Frame with Masonry Infill). Earthq Spectra: August 2012, Vol. 28, No. 3, pp. 835-858

[20] Dutu A, Sakata H, Yamazaki Y. Experimental study on timber framed masonry structures. In: Proceedings of the 1st international symposium on historic earthquake-resistant timber frames in the Mediterranean region (H.Ea.R.T.2013), November 4-5, University of Calabria, Italy; 2013

[21] Meireles H, Bento R, Cattari S, Lagomarsino S. A hysteretic model for "frontal" walls in Pombalino buildings. Bull Earthq Eng, 2012; 10:1481-1502

[22] Ruggieri N, Zinno R. Behaviour of the Borbone Constructive System under Cycling Loading. Preliminary Report. In Proceedings of International Conference on Historic EarthquakeResistant Timber Frames in the Mediterranean Area, Unical, Cosenza, 2013

[23] Vieux-Champagne F, Sieffert Y, Grange S, Polastri A, Ceccotti A, Daudeville L. Experimental analysisof seismic resistance of timber-framed structures with stones and earth infill. Eng Struct, $2014 ; 69: 102-115$

[24] Rizzo A, De Lorenzis L. Behavior and capacity of RC beams strengthened in shear with NSM FRP reinforcement. Constr \& Build Mater 2009; 23 (4):1555-1567.

[25] Poletti E, Vasconcelos G, Jorge M. Full scale experimental testing of retrofitting techniques in Portuguese "Pombalino" traditional timber frame walls. J Earthq Eng 2014, 18(4): 553 - 579.

[26] Eurocode 5. EN 1995-1-1:2004. Eurocode 5: Design of timber structures - Part 1-1: General Common rules and rules for buildings, CEN, Brussels, 2004.

[27] VICAT. Prompt Technical Document. Special Binders VICAT, 2003. http://www.womersleys.co.uk/acatalog/prompt_technical.pdf (last accessed on 2013/04/19).

[28] MAPEI Mapewood Paste 140. Thixotropic epoxy adhesive for the restoration of timber structural elements. 2002. (available at: http://www.mapei.com/public/COM/products/1503 GB.pdf)

[29] BS EN 10002-1. Metallic materials. Tensile testing - Part 1: Method of test at ambient temperature. 2001. 
[30] Eurocode 1, EN1991-1-1:2002. Actions on structures-part 1-1: general actions-densities, self-weight, imposed loads for buildings. CEN, Brussels; 2002.

[31] ISO 21581. Timber structures - Static and cyclic lateral load test method for shear walls. 2010.

[32] Tomaževic M. Earthquake resistant design of masonry buildings. London: Imperial College Press; 1999.

[33] Vasconcelos G, Lourenço PB. In-Plane Experimental Behavior of Stone Masonry Walls under Cyclic Loading. J Struct Eng 2009; 135(10):1269-1277.

[34] Piazza M, Tomasi R, Modena R. Timber structures (in Italian). Milan: Biblioteca Tecnica Hoepli; 2005.

[35] Magenes G, Calvi GM. In-plane seismic response of brick masonry walls. Earthq Eng and Struct Dyn 1997; 26:1091-1112.

[36] Haach VG, Vasconcelos G, Lourenço PB. Parametrical study of masonry walls subjected to inplane loading through numerical modeling. Eng Struct 2011; 33(4): 1377-1389. 